\title{
Partial discharge patterns related to surface deterioration in voids in epoxy
}

\author{
Holbøll, Joachim; Henriksen, Mogens
}

Published in:

I E E E International Symposium on Electrical Insulation. Conference Record

Link to article, DOI:

10.1109/ELINSL.1990.109721

Publication date:

1990

Document Version

Publisher's PDF, also known as Version of record

Link back to DTU Orbit

Citation (APA):

Holbøll, J., \& Henriksen, M. (1990). Partial discharge patterns related to surface deterioration in voids in epoxy. I E E E International Symposium on Electrical Insulation. Conference Record, 115-119.

https://doi.org/10.1109/ELINSL.1990.109721

\section{General rights}

Copyright and moral rights for the publications made accessible in the public portal are retained by the authors and/or other copyright owners and it is a condition of accessing publications that users recognise and abide by the legal requirements associated with these rights.

- Users may download and print one copy of any publication from the public portal for the purpose of private study or research.

- You may not further distribute the material or use it for any profit-making activity or commercial gain

- You may freely distribute the URL identifying the publication in the public portal

If you believe that this document breaches copyright please contact us providing details, and we will remove access to the work immediately and investigate your claim. 


\section{Conference Record of the 1990 IEEE International Symposium on Electrical Insulation, Toronto, Canada, June 3-6, 1990 PARTIAL DISCHARGE PATTERNS RELATED TO SURFACE DETERIORATION IN VOIDS IN EPOXY.}

J.T. Holb $\varnothing 1 l$ and M. Henriksen,

Electric Power Engineering Department, Technical University of Denmark Building 325,

DK-2800 Lyngby, Denmark

\section{Abstract:}

Results are presented from an investigation to determine the relationship between changes in partial discharge patterns and the surface deterioration process taking place in small naturally formed spherical voids in epoxy plastic. The voids were exposed to such a moderate electric stress above inception level, where partial discharges were present for more than 1500 hours.

Two types of electrical tree growth were found, one the "bush-like" tree, the other a single "channel-like" tree, which led to very different partial discharge patterns.

\section{Introduction}

In this report is described results from a long term test on partial discharges in spherical voids in epoxy and the resulting deterioration of the void surfaces. Pulse height and pulse phase analyses have been performed on artificially produced, but naturally formed, spherical voids with diameters ranging from 1.2 to $1.3 \mathrm{~mm}$ in diameter. These analyses have then been compared with an investigation into the void surface deterioration that has taken place using an optical microscope.The epoxy used for this test was a standard type Bisphenol-A Diglycidylether (Ciba-Geigy, CY225) used together with an acidanhydride curing agent (Ciba-Geigy, HY925)

The PD-tests were performed simultaneously on five test specimens (designated $1,2,3,4,5$ ) and the surface studies were performed on specimens 1 to 4 . The test was terminated after 1518 hours because one of the test specimens showed a high PD activity leading to the assumption than an eminent failure was to be expected in said specimen.

\section{Test Set-Up}

The test specimens all had a thickness of $5 \mathrm{~mm}$ and they all contained one gasfilled spherical void in their centres with cavity diameters of 1.2 to $1.3 \mathrm{~mm}$. When manufacturing the voids, clean medical air was used at a pressure of one bar absolute.

The specimens were placed in a test-chamber containing an SF6 atmosphere at 4 bar absolute when exposed to a $50 \mathrm{~Hz}$ test voltage of $21 \mathrm{kV}$ (rms). A $50 \mathrm{Ohm}$ resistor connecting the measuring electrode to ground was used as detection impedance. Via this resistor, the PD pulses used for the pulse height and pulse phase analysis were fed into the measuring system.

An HP86 Computer acted as the test set-up controller and data storage organiser, as shown in Fig. 1.

\section{Pulse Analyses:}

The tests showed that the PD pulse had a rise time of no more than $1 \mathrm{~ns}$ and the max pulse height was about 3 volts. The measuring system's response to such fast pulses was investigated and showed a linear relationship between the pulse area $I^{*} t$ and the actual recorded pulse height. This acts as the basis for the calibration of the measuring system which means that there exists a direct relationship between the recorded pulse height and the charge displacement apparent charge $(\mathrm{pC})$. The height analyses were performed for both positive and negative pulses.

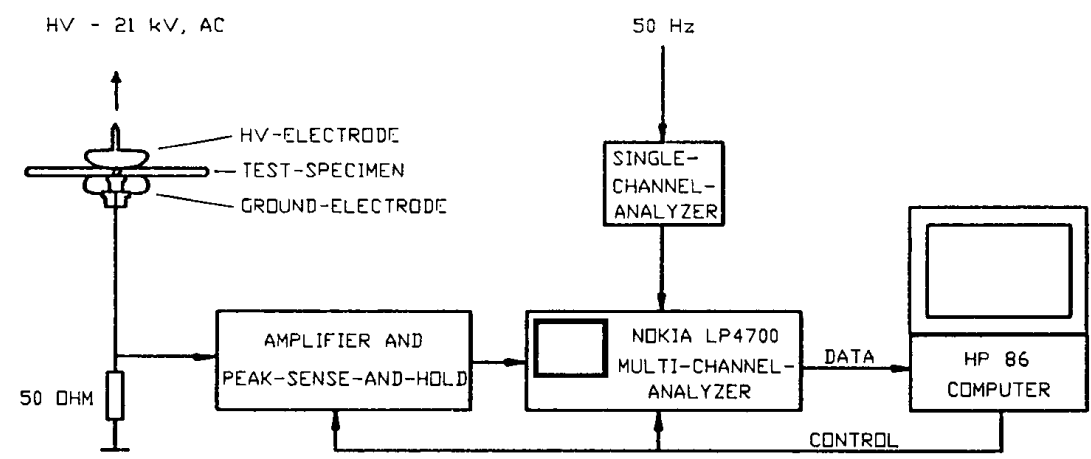

Fig.1: Test Set-Up

CH2727-6/90/0000-115 \$1.00 @ 1990 IEEE 
In the phase analysis, the PD-activities are directly related to the applied test-voltage, which means that for positive going voltage $(-5 \mathrm{~ms}$ to $+5 \mathrm{~ms})$, positive pulses are recorded and for negative going voltage $(+5 \mathrm{~ms}$ to $+15 \mathrm{~ms})$, negative pulses are recorded and the two separate analyses are combined to form a total phase analysis, but fundamentally the phase analysis is just another way of presenting the height analysis data, and should basically only be used on single voids. The measuring time for both the height and phase analyses was increased from $1 \mathrm{~min}$. at the beginning of the test to 4 minutes after 400 hours into the test.

The frequency at which the tests were performed on the single specimen were determined from the PulseRepetition-Rate based on one-minute "orientation" tests of the total number of recorded pulses.

\section{PD Test Results}

\section{Height Analysis}

The height analysis showed the following typical pattern for all the specimens:

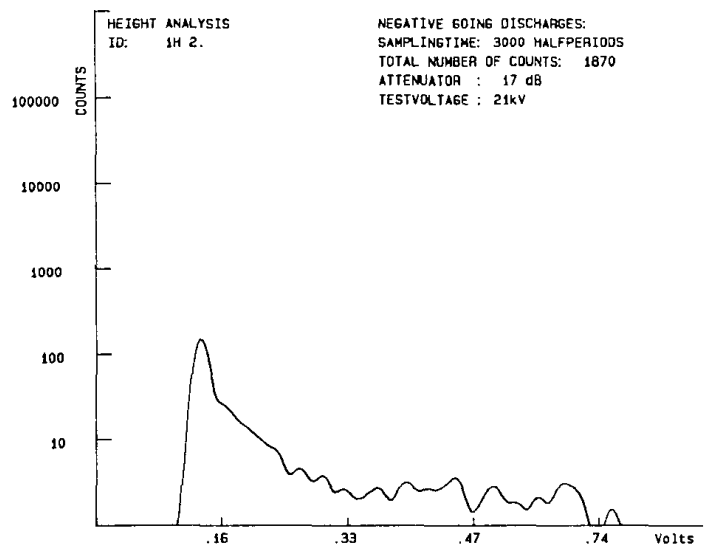

Fig.2: Height Analysis, Specimen 1, 2 hours.

Except for variations in the total number of pulses detected, this pattern was unchanged during the whole test period. The detected pulse height corresponds to max. "apparent charge" on the testelectrode of $89 \mathrm{pC}($ Specimen No. 1) and 191 $\mathrm{pC}($ Specimen No. 5) and is independent of the polarity. Regarding Specimen No. 2, a very high PD activity was detected after 1518 hours into the test, and at the same time, a very pronounced difference in the total number of positive and negative pulses was observed, as shown in Fig. 3.a. and Fig. 3.b. respectively. As can be seen almost 10 times more positive pulses were detected than negative pulses.

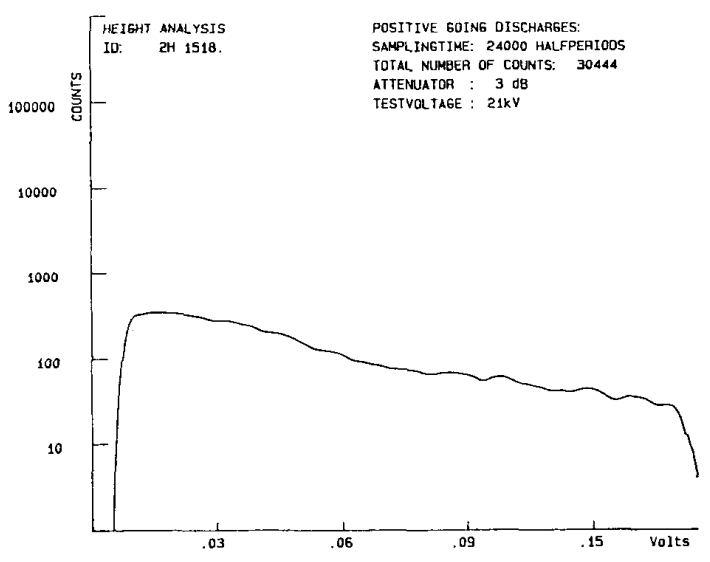

Fig.3.a.: Height Analysis, Spec. 2, 1518 Hours, Pos. Pulses.

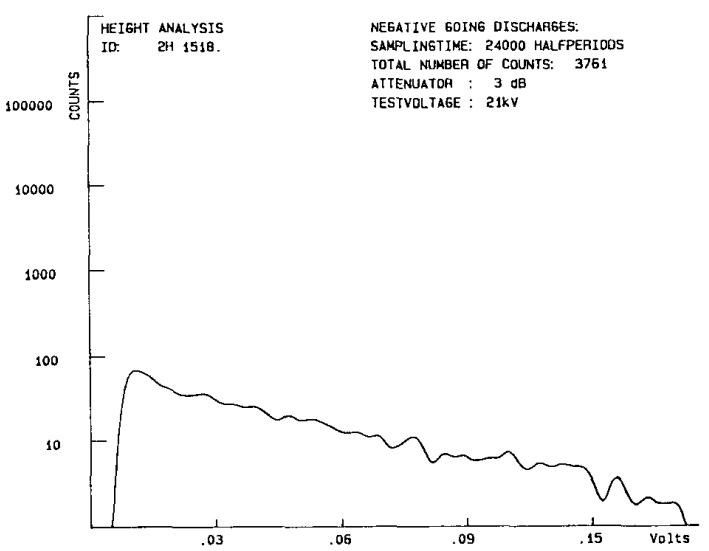

Fig.3.b.: Height Analysis, Spec. 2, 1518 Hours, Neg. Pulses.

\section{Phase analysis}

For all the 5 test specimens the phase analysis also showed a general trend as a function of time, as shown in Figs.4.a to 4.e, recorded after $1,20,50,300$ and 1000 hours for test specimen No. 1.

As can be seen the activity decreases with time, but, at the same time, first three (5 Hours) and later five (300 Hours) maximums occur. This has been reported earlier [1], and could possibly indicate a decrease in the inception voltage. This is also somewhat indicated by the change in location of PD pulses in respect to the test voltage maximums. After one hour the PD inception does occur $1.5 \mathrm{~ms}$ before the test voltage zero passes, but after 50 hours this has moved to 2 $\mathrm{ms}$ and after 1000 hours to $2.5 \mathrm{~ms}$. If it can be assumed that the remaining voltage is zero [2], it can be calculated that this corresponds to a decrease in inception voltage of $10 \%$ after 50 hours and $20 \%$ after 1000 hours in respect to the initial value. 


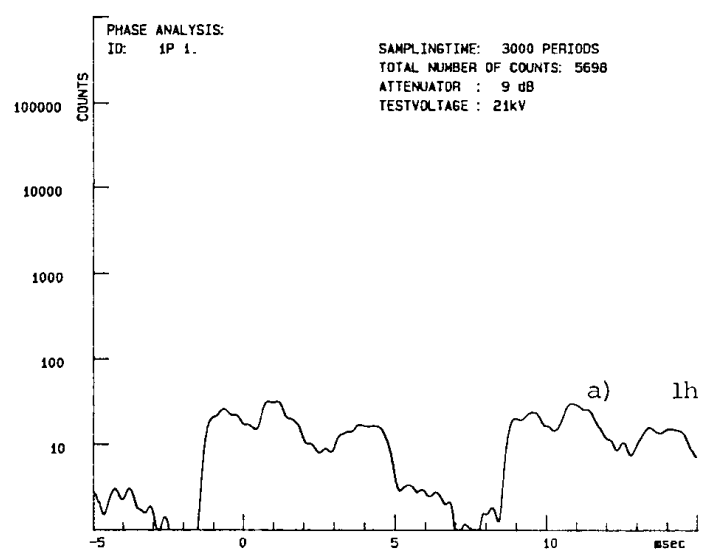

10

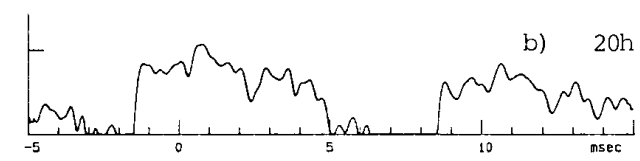

10

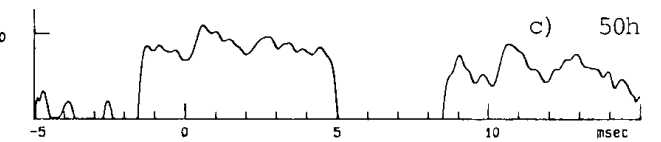

10

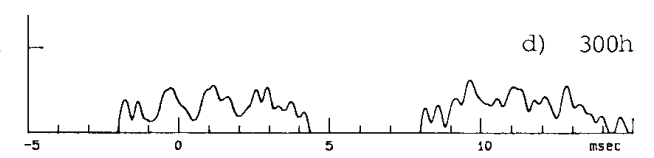

10

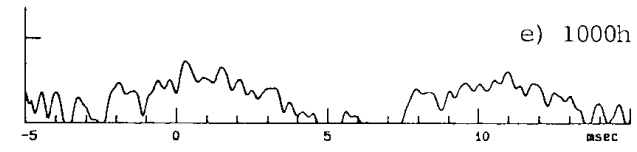

Fig.4.a-e.: Phaseanalysis, Specimen 1, 1 to 1000 Hours

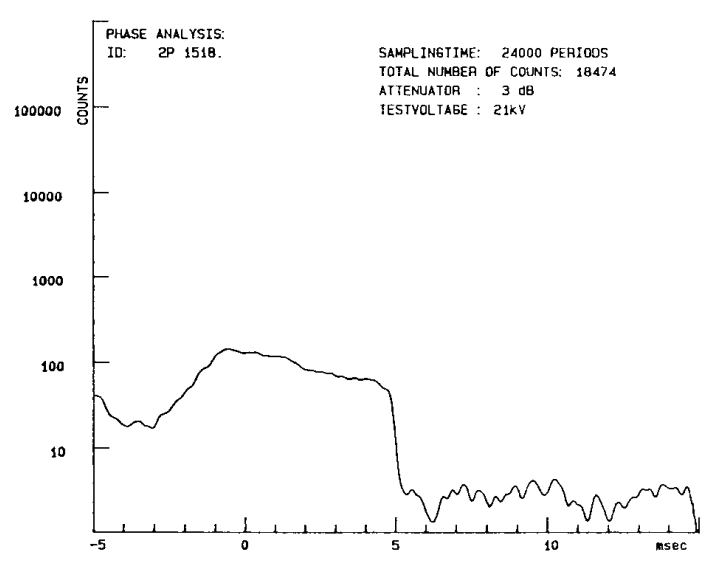

Fig.5: Phaseanalysis, Specimen 2, 1518 Hours.

Again, test specimen No. 2 deviates from this behaviour after 1518 hours, as shown in Fig. 5 above. As can also be seen, the inception voltage can no longer be determined, but is much lower than the initial value recorded.

\section{Pulse-Repetitition-Rate.}

The pulse-repetition-rate (the discharge activity) for the five test specimens behaved with time as shown in Fig.6 below.

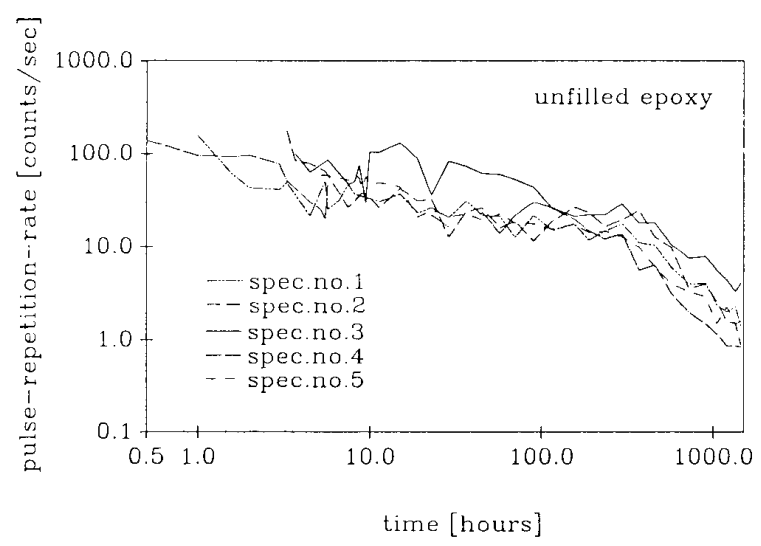

Fig.6: Pulse-Repetition-Rate, Specimen 1-5

The PRR decreases from an initial value of 100 counts $/ \mathrm{sec}$ to about 1 count/sec. after 1500 hours. Specimens $1,2,4$ and 5 behave the same way, whereas specimen 3 shows, over long periods, a much higher activity (approximately 2.5 times higher). The time to inception of PD after voltage application (time lag) is also shown; it varies from 0.5 hours to 5 hours.

\section{Surface Investigations with Light Microscope.}

In order to determine the void surface condition before start of PD activity, voids made with the same epoxy were opened up and examined with SEM. A magnification of 10,000 showed an absolutely perfect void surface.

The surface investigations here reported were performed using a light microscope (type Zeiss NU2) on the void surfaces of specimen $1,2,3$ and 4 after the 1518 hours with voltage. The locations of the investigated areas are related to the applied electric field as indicated in Fig. 7.

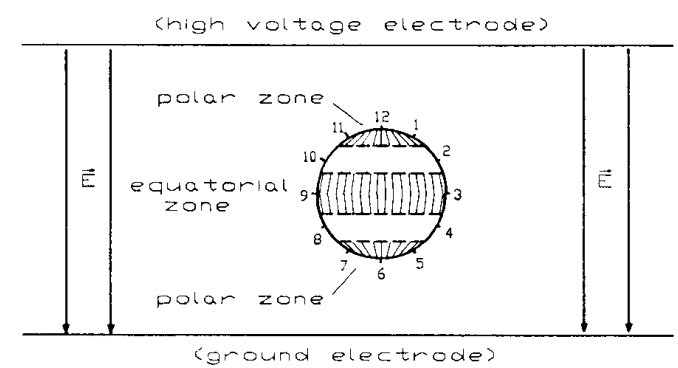

Fig.7:The Void Orientation in Respect to the Applied Electric Field.

After a preliminary evaluation of the void surface deterioration after 1518 hours with voltage from the outside using a stereo microscope, the voids were opened up in such a way that the "interesting" areas could be directly observed with 
the light microscope. Specimens 2,3 and 4 were opened along the equatorial plane giving access to the polar zone, whereas specimen 1 was opened along the polar plane giving access to the equator zone.

When looking from the outside at the void surface of specimen 1, about 10 "star-like" patterns were observed in the equator zone. The same patterns were also found after the void was opened, Fig. 8, and it is alssumed that the patterns are formed by oxalic acid as reported in [3] and [4] The same "star-like" patterns were also found in the equator zone of specimens 2 and 4.

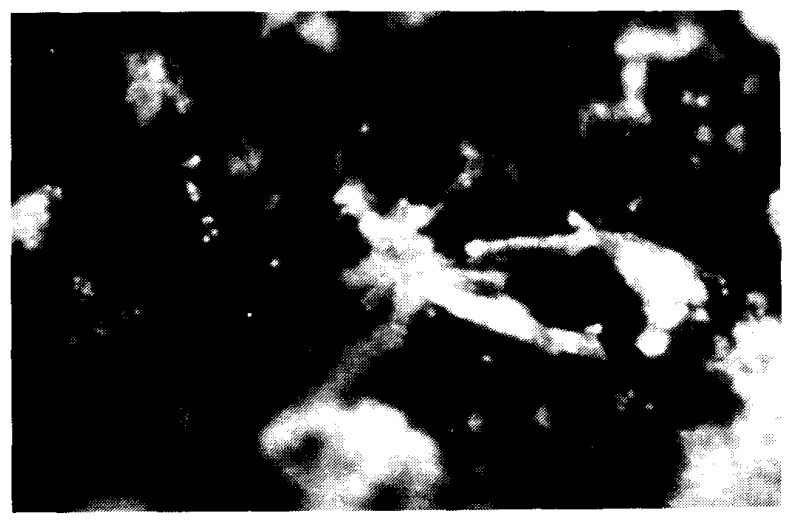

Fig.8: Specimen 1, Equatorial Zone, Crystal Length 33 um.

Regarding specimen No. 2, a "tree-like" crystal was found in the polar zone at position 5 , near the measuring electrode, and in the vicinity of the crystal, a severe surface deterioration had started, Fig.9.

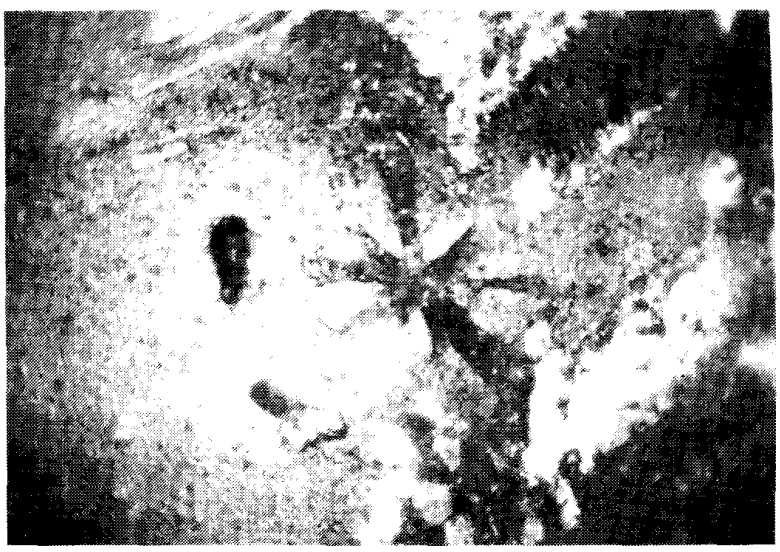

Fig.9.: Spec. 2, Polar Zone, Tree-like Crystal, Length 64 um

In Fig. 10 is shown the polar zone of specimen 3 from position 10 to 2 . It shows that only certain areas have been affected by the partial discharge activity, but on the other hand the affected areas have been greatly deteriorated.

No form of crystal formation was found in the equator zone of this specimen.

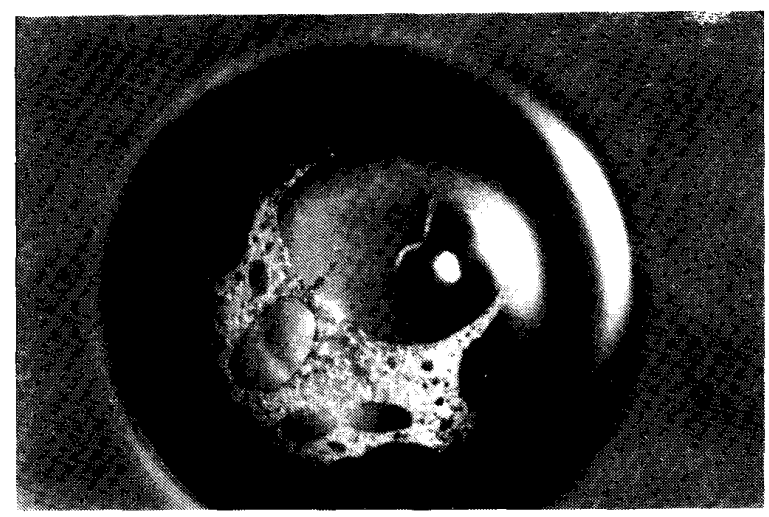

Fig. 10: Specimen 3 before opening up the void, Polar Zone.

When observing the void of specimen 4 in the microscope from the outside, a black "channel-like" structure was seen, starting close to (perhaps at) the void surface at position 2 with the direction toward the high voltage electrode, as can be seen in Fig.11. On opening up the void this black "channel-like" structure was found to be some sort of a "flat twisted" channel, with a diameter of 2 um close to the void surface, see Fig.12.

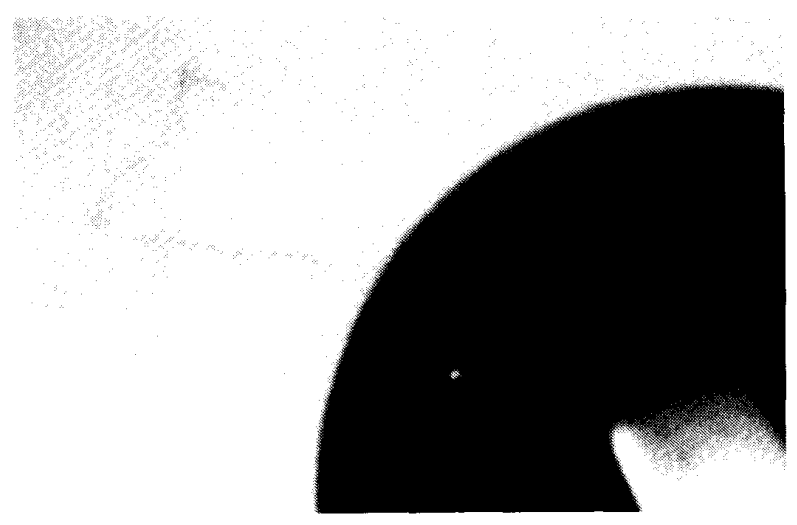

Fig.11: Specimen 4, with black "channel-like" structure.

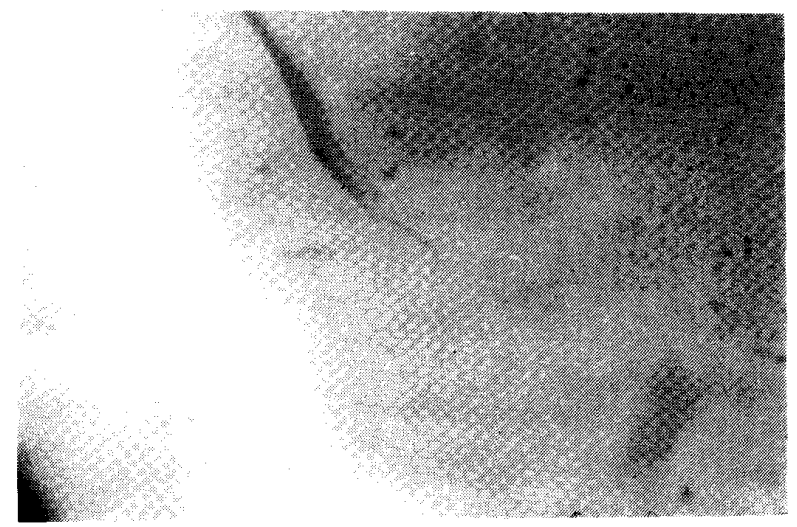

Fig. 12: Specimen 4

Observing the "Channel" From the Void Side. 
In table no. 1 is shown in condensed form, the most important results from the partial discharge measurements and the microscopic investigation of the deteriorated void surfaces. "Normal" designates what has been found in all the test specimens except for specimen no. 3 .

Table 1

\begin{tabular}{|c|c|c|}
\hline Specimen & Deterioration & PD-analysis \\
\hline 1 & $\begin{array}{c}\text { Normal } \\
\text { Surface deposit } \\
\text { Crystals in Equator Zone }\end{array}$ & Normal \\
\hline 2 & $\begin{array}{c}\text { Normal + Tree } \\
\text { Surface deposit } \\
\text { Crystals in Equator Zone }\end{array}$ & $\begin{array}{c}\text { For a period } \\
\text { High PD-activity } \\
\text { Non Symmetric PPD }\end{array}$ \\
\hline 3 & $\begin{array}{l}\text { Surface Deterioration } \\
\text { Only in Certain Areas } \\
\text { Rough Surface }\end{array}$ & High PD-activity \\
\hline 4 & $\begin{array}{c}\text { Normal }+ \text { Tree(black) } \\
\text { Surface deposit } \\
\text { Crystals in Equator Zone }\end{array}$ & Normal \\
\hline
\end{tabular}

\section{Discussion of Results}

\section{The Discharge Patterns.}

The changes in the discharge patterns are most likely caused by the decrease in inception voltage. This decrease is most likely influenced by the changes in the void surface structure causing changes in the test voltage distribution and space charge distribution across the test specimen.

The decreasing PRR can be explained by either a void gas temperature increase or an increase in the void gas pressure caused by gasformation from decomposed surface material or a combination of both. This assumption is somewhat supported by the fact that an increase in PRR is detected when reapplying the test voltage after some time without voltage. Perhaps also a change in the pulse type is to be expected.

\section{The Relationship Between Surface Deterioration and Discharge Patterns.}

The crystal in test specimen 2 could have been the reason for the very high PD activity observed for this specimen because the location of the crystal could have led to field enhancement, thereby leading to a much higher activity when positive than negative. Perhaps the crystal is the first stage of an electrical tree formation.
Regarding test specimen no. 3: had high PRR, only part of the surface had deterioration and no crystal-like patterns found in the equator zone, which could indicate that the surface deterioration in this specimen has been different from that of the four other specimens, this being supported by the large variation in pulse height. All this makes the explanation of the nature of the surface deterioration caused by $P D$ in spherical voids very difficult, when keeping in mind that the void diameters and the production parameter were kept the same. A very alarming result was that the PD signal from test specimen no. 4 did not give any indication at all of a channel growth.

In test specimens 1,2 and 4 , evenly distributed surface layers were found, which were rather easy to remove. An assumption could be that these layers consist of one of the by-products from the deteriorated surfaces, but this needs to be investigated further using e.g. an X-ray analysing method.

\section{Conclusion}

It has been found that there exists some relationships between partial discharge activity measurements and the actual surface deterioration of spherical voids in epoxy.

A direct relationship was found between changes in partial discharge patterns and the elapsed time with partial discharges.

Formation of crystals on a void surface leads to an immediate and easy to detect increase in the partial discharge activity with a following severe surface deterioration (deep pit formations) in the vicinity of the crystal. Contrary to this, the formation of a "black channel-like tree" from the void towards the high voltage test electrode, does not give any indication of its formation, unfortunately.

\section{References}

[1] M. Henriksen, Partial Discharges in Spherical Cavities in Epoxy Resin. Technical University of Denmark, Power Engineering Department, 1982.

[2] R. Bartnikas \& E.J. McMahon, Engineering Dielectrics. Vol.1. Corona Measurement and Interoretation. ASTM 1979.

[3] Steen Christensen, Electrical Deterioration of Epoxy Plastic as_a Result of Internal Dischartges. Technical University of Denmark, Power Engineering Department, 1985.

[4] Olav Nørholm, Deterioration of Epoxy Plastic by Partial Discharges (in Danish). Technical University of Denmark, Power Engineering Department, 1969. 